\title{
Identification and Characterization of Autoreactive T Cell Responses to Bullous Pemphigoid Antigen 2 in Patients and Healthy Controls
}

\author{
Lioba Büdinger, ${ }^{\star}$ Luca Borradori,, Carole Yee, ${ }^{\S}$ Rüdiger Eming, ${ }^{\star}$ Stanislav Ferencik, ${ }^{\|}$Hans Grosse-Wilde," Hans F. Merk, ${ }^{\star}$ \\ Kim Yancey, $\$$ and Michael Hertl ${ }^{\star}$ \\ *Hautklinik, Universitätsklinikum der RWTH Aachen, D-52074 Aachen, Germany; ${ }^{\ddagger}$ Clinique de Dermatologie, Hopital Cantonal \\ Universitaire, CH-1211 Geneve, Switzerland; ${ }^{\S}$ Dermatology Branch, National Cancer Institute, Bethesda, Maryland 20892-1908; and \\ Institut für Immunologie, Universitätsklinikum Essen, D-45122 Essen, Germany
}

\begin{abstract}
Antibodies against the extracellular domain of bullous pemphigoid antigen 2 (BPAG2) are thought to play a key role in the pathogenesis of bullous pemphigoid (BP), the most frequent autoimmune bullous disease of the skin. Autoreactive $\mathrm{T}$ cell responses to BPAG2 were investigated in $16 \mathrm{BP}$ patients and 24 healthy controls by coculture of PBMC with two recombinant BPAG2 proteins (extracellular domain of BPAG2). Primary in vitro $T$ cell responses to BPAG2 were observed in 10/12 BP patients expressing the BP-associated HLA-DQB1*0301 allele and 8/10 DQB1*0301 positive healthy individuals. $\mathrm{DQB} 1 * 0301$ also restricted three autoreactive $\mathrm{T}$ cell lines from two BP patients and a healthy donor. In contrast, PBMC from 14 normal patients carrying HLA class II alleles other than DQB1*0301 were not stimulated by BPAG2. Autoreactive BPAG2-specific $\mathrm{CD}^{+}{ }^{+} \mathrm{T}$ cell lines and clones from five BP patients produced both Th1 and Th2 cytokines, whereas three autoreactive $T$ cell lines from three DQB1*0301 positive normal patients produced exclusively IFN- $\gamma$. The absence of BPAG2-specific Th2 cells in healthy individuals strongly suggests that autoreactive Th2 responses to BPAG2 are restricted to $\mathrm{BP}$ patients and may thus be critical in the pathogenesis of BP. (J. Clin. Invest. 1998. 102:2082-2089.) Key words: hemidesmosome • extracellular domain • autoreactive Th1/Th2 cells • cytokines • HLA class II restriction
\end{abstract}

\section{Introduction}

Bullous pemphigoid $(\mathrm{BP})^{1}$ is the most frequent autoimmune blistering disease of the skin. Clinical features of BP include

Address correspondence to Michael Hertl, M.D., Hautklinik der RWTH, Pauwelsstr. 30, D-52074 Aachen, Germany. Phone: 49-24180-89162; FAX: 49-241-8888-538; E-mail: MHertl@compuserve.com

Received for publication 6 March 1998 and accepted in revised form 21 October 1998.

1. Abbreviations used in this paper: Ag, antigen; APC, antigen-presenting cell; AZA, azathioprine; BP, bullous pemphigoid; BPAG1, bullous pemphigoid antigen 1 (BP230); BPAG2, bullous pemphigoid antigen 2 (BP180); BV13, baculoprotein containing the ECD (residues 485-1430) of BPAG2 linked to GST and 6x His tag; BV4, baculoprotein containing residues 804-1430 of the ECD of BPAG2 linked to FLAG peptide tag; Dsg3, desmoglein 3; ECD, extracellular domain; GST, glutathione-S-transferase; MP, methylprednisone; PV, pemphigus vulgaris; SI, stimulation index; TT, tetanus toxoid.

The Journal of Clinical Investigation

Volume 102, Number 12, December 1998, 2082-2089

http://www.jci.org generalized, tense blisters on normal or erythematous skin and in some cases, blisters or erosions of the mucous membranes $(1,2)$. A hallmark of BP is the presence of circulating autoantibodies directed against two components of hemidesmosomes, BP antigen 1 (BPAG1, also BP230) and BP antigen 2 (BPAG2, also BP180 or type XVII collagen) (3-5). Hemidesmosomes are multiprotein junctional complexes that play a key role in promoting adhesion of epithelial cells to the underlying basement membrane and connect elements of the cytoskeleton to the extracellular matrix in skin and other stratified epithelia (3-5). BPAG1, a cytoplasmatic plaque constituent of these complexes, belongs to the plakin family of intermediate filament binding proteins and has been shown to associate with intermediate filaments in vitro (6). In contrast, BPAG2 is a type II transmembrane protein which may serve as a cell matrix receptor for a yet unrecognized ligand within the extracellular matrix (7). The extracellular $\mathrm{COOH}$-terminal portion of BPAG2 contains 15 interrupted collagenous domains that may form collagen-like triple helices (7). Support for the idea that BPAG2 plays an important role in promoting cell adhesion and the assembly of hemidesmosomes derives from transfection studies $(8,9)$ as well as from studies of patients with generalized atrophic benign epidermolysis bullosa, an inherited subepidermal blistering disorder characterized by defective dermo-epidermal adhesion and the formation of rudimentary hemidesmosomes (10). Although almost all autoantibodies from BP sera target BPAG1, and, in $~ 70 \%$ of the cases, BPAG2, their importance in the pathogenesis of the disease has remained unclear. Recent studies have shown that rabbit Abs raised against a major immunodominant site of the extracellular domain (ECD) of BPAG2 adjacent to the membrane spanning region are able to induce, via complement activation, subepidermal blisters, when injected into neonatal mice $(11,12)$. In humans, the major immunodominant site of BPAG2 recognized by patients' IgG autoantibody is located within the noncollagenous NC16A domain close to the transmembranous region of the ECD of BPAG2 (Fig. 1) (13-15). These observations strongly suggest that autoantibodies against BPAG2 are pathogenic and are responsible for dermo-epidermal separation in BP.

$\mathrm{T}$ lymphocytes are critical in the induction and regulation of both cell-mediated and humoral immune responses. There is strong evidence that $\mathrm{T}$ lymphocytes are also involved in the initiation and perpetuation of autoimmune responses $(16,17)$. Previous studies showed that autoreactive $\mathrm{T}$ cells may provide help to B cells to produce autoantibodies that are critical in the pathogenesis of several autoimmune diseases, such as myasthenia gravis (16), autoimmune thyroiditis (17), and pemphigus vulgaris (PV) $(18,19)$. These observations prompted us to investigate whether patients with $\mathrm{BP}$ exhibit autoreactive $\mathrm{T}$ cell responses to the putative autoantigen of BP, BPAG2. Recognition of epitopes of BPAG2 may be crucial for the initia- 


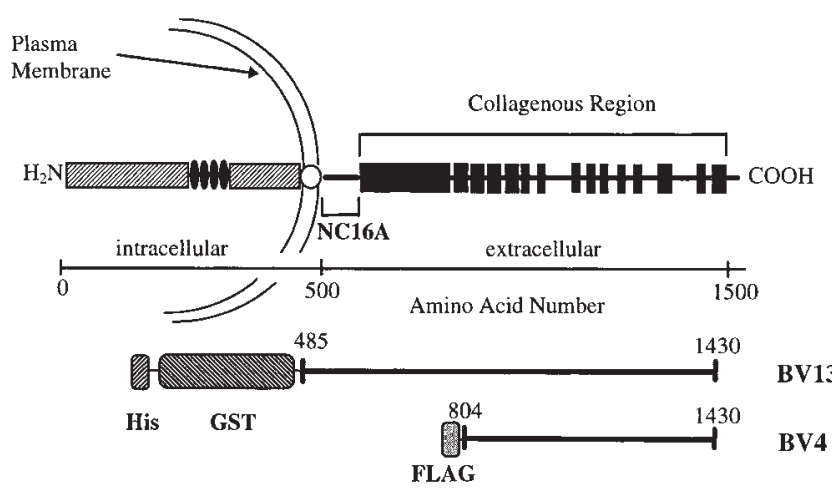

Figure 1. Schematic representation of the human BPAG2 autoantigen and the recombinant BPAG2 proteins BV4 and BV13. BPAG2 is a transmembranous type II protein with a $\mathrm{COOH}$-terminal extracellular portion which contains 15 interrupted collagenous domains (adapted from reference 7). The baculovirus-derived protein BV13 consists of almost the entire ECD of BPAG2 (residues 485-1430) and is linked at its $\mathrm{NH}_{2}$ terminus to a GST and 6x His tag. BV4 encompasses the distal two-thirds of the ECD of BPAG2 (residues 8041430) and is linked to a FLAG tag at the $\mathrm{NH}_{2}$ terminus.

tion and perpetuation of BPAG2-specific $\mathrm{T}$ cell responses resulting in the activation of $\mathrm{B}$ cells that produce BPAG2-specific autoantibodies.

In this study, we identified autoreactive $\mathrm{T}$ cell responses to the ECD of BPAG2 in 13 of 16 patients with BP using two baculovirus-encoded recombinant forms of BPAG2. 10 of 12 BPAG2-reactive HLA-typed BP patients carried the HLA class
II allele DQB1*0301 which has been shown to be prevalent in BP (20). Strikingly, eight healthy carriers of DQB1*0301 also showed $\mathrm{T}$ cell responses to BPAG2 whereas PBMC from 14 normal patients carrying HLA class II alleles other than DQB1*0301 were not stimulated by BPAG2. Finally, our findings demonstrated that BPAG2-specific $\mathrm{T}$ cell lines and clones from five BP patients produced both Th1 and Th2 cytokines whereas autoreactive $T$ cells from three normal patients exclusively produced the Th1 cytokine IFN- $\gamma$.

\section{Methods}

Patients and controls. Adult patients with generalized BP $(n=16)$ and healthy volunteers $(n=24)$ were studied. The clinical diagnosis of BP was confirmed in all patients by $(a)$ histopathology (subepidermal blisters), (b) direct immunofluorescence microscopy of perilesional skin (IgG deposits at the dermal-epidermal junction), (c) the detection of circulating autoantibodies either by indirect immunofluorescence microscopy (IgG binding to the epidermal site of $1 \mathrm{M} \mathrm{NaCl}$ separated normal human skin), or $(d)$ serum reactivity in a recently described ELISA (21) with the recombinant protein BV13 encompassing the ECD of BPAG2 (Table I). 13 of $16 \mathrm{BP}$ patients had active disease with blistering of the skin whereas the remaining 3 patients had no clinical signs of active disease (Table I). All of the patients with skin lesions were under immunosuppressive therapy which generally consisted of a combination of methylprednisone (MP; initial daily dose of $60 \mathrm{mg}$ ) and azathioprine (AZA, $100 \mathrm{mg} / \mathrm{d}$ ). MP was tapered to a maintenance dose of 4-8 mg within 8-12 wk whereas AZA was continued at a daily dose of $25-100 \mathrm{mg} / \mathrm{d}$. The control subjects were healthy individuals who had no personal or family history of $\mathrm{BP}(n=$ 24). All patients and controls gave informed consent to participate in this study. HLA class II typings of BP patients (Table I) and healthy controls (Table II) were done by the PCR-SSP technique $(22,23)$.

Table I. Clinical Status, HLA Class II Alleles, and Proliferative Responses to BPAG2 of Peripheral Blood Lymphocytes from 16 Patients with BP

\begin{tabular}{|c|c|c|c|c|c|c|c|c|c|c|}
\hline \multicolumn{2}{|c|}{ Patients } & \multicolumn{3}{|c|}{ Clinical status } & \multicolumn{2}{|c|}{ HLA class II alleles } & \multicolumn{3}{|c|}{ First $\mathrm{T}$ cell response $\mathrm{s}^{\S}$} & \multirow{2}{*}{$\begin{array}{l}\text { BPAG2 } \\
\text { AB titer }\end{array}$} \\
\hline BP\# & Age & Skin lesions* & Duration & Treatment $t^{\ddagger}$ & HLA-DRB1 & HLA-DQB1 & BV13\| & PVhis $\|$ & $\mathrm{TT}^{\|}$ & \\
\hline & $y r$ & & & & & & & & & \\
\hline BP2 & 54 & Trunk & $2 \mathrm{mo}$ & MP $4 \mathrm{mg}$ & 0101,1101 & $\mathbf{0 3 0 1}, 0501$ & 18.8 & 0.9 & 8.5 & 200 \\
\hline BP5 & 75 & Trunk, oral mucosa & $6 \mathrm{mo}$ & MTX $15 \mathrm{mg}$ & 0901,- & 0303,- & 2.7 & 1.8 & 35.4 & 20 \\
\hline BP10 & 52 & Face, upper back & $1 \mathrm{mo}$ & MP 60 mg & 1101,1301 & $\mathbf{0 3 0 1}, 0603$ & 2.5 & 1.4 & 0.7 & 20 \\
\hline BP11 & 88 & Integument, mouth & $5 \mathrm{wk}$ & MP $42 \mathrm{mg}$, AZA $100 \mathrm{mg}$ & 1101,1301 & $\mathbf{0 3 0 1}, 0603$ & 3.5 & 1.3 & 4.0 & 400 \\
\hline $\mathrm{BP} 17$ & 68 & Face, vulva & $4 \mathrm{yr}$ & MP $12 \mathrm{mg}$, AZA $100 \mathrm{mg}$ & 0301,1104 & $0201, \mathbf{0 3 0 1}$ & 5.2 & 1.0 & 0.9 & 200 \\
\hline BP18 & 62 & None & $6 \mathrm{yr}$ & None & NT & NT & 4.1 & 1.5 & 5.1 & 100 \\
\hline BP20 & 62 & Extremities & $4 \mathrm{wk}$ & MP 4 mg & 0101,1101 & $\mathbf{0 3 0 1}, 0501$ & 10.0 & 1.7 & $\mathbf{1 7 . 3}$ & 200 \\
\hline BP21 & 75 & None & $39 \mathrm{mo}$ & MP $4 \mathrm{mg}$, AZA $25 \mathrm{mg}$ & 0101,1102 & $\mathbf{0 3 0 1}, 0501$ & 3.8 & 1.6 & 0.9 & 200 \\
\hline BP24 & 79 & None & $29 \mathrm{mo}$ & AZA $50 \mathrm{mg}$ & 0101,0401 & $\mathbf{0 3 0 1}, 0501$ & 11.2 & 2.0 & 2.1 & 100 \\
\hline BP28 & 56 & Arms, chest & $8 w k$ & MP $16 \mathrm{mg}$, AZA $50 \mathrm{mg}$ & 1101,1501 & $\mathbf{0 3 0 1}, 0602$ & 13.9 & 0.6 & 28.7 & 400 \\
\hline BP42 & 62 & Chest, arms & $30 \mathrm{mo}$ & None & $1101,-$ & $0301,-$ & 14.0 & 1.1 & 14.6 & 400 \\
\hline BP49 & 85 & Trunk, arms & $1 \mathrm{wk}$ & MP $16 \mathrm{mg}$ & 0301,1101 & $0201, \mathbf{0 3 0 1}$ & 3.1 & 2.3 & 1.1 & 50 \\
\hline BP75 & 56 & Legs, mouth & $4 \mathrm{wk}$ & MP $52 \mathrm{mg}$, DADPS $150 \mathrm{mg}$ & 0101,0102 & 0501,- & 4.6 & 0.5 & 34.0 & 100 \\
\hline BP77 & 78 & Upper trunk & $6 \mathrm{wk}$ & MP 40 mg, AZA $100 \mathrm{mg}$ & 0101,1102 & $\mathbf{0 3 0 1}, 0501$ & 2.3 & 0.2 & 0.2 & 50 \\
\hline BP78 & 76 & Trunk & $3 \mathrm{mo}$ & MP $52 \mathrm{mg}$, DADPS $100 \mathrm{mg}$ & 0408,1301 & $\mathbf{0 3 0 1}, 0603$ & 3.3 & 1.3 & 2.5 & 50 \\
\hline BP108 & 77 & Trunk, arms & $6 \mathrm{mo}$ & None & 0102,1501 & 0501,0602 & 8.6 & 6.4 & 7.5 & 100 \\
\hline
\end{tabular}

* BP patients exhibited blisters or erosions at the sites listed above. ${ }^{\star}$ Daily doses of MP, AZA, diaminodiphenylsulfone (DADPS); weekly dose of methotrexate $(M T X) .{ }^{\S}$ Background stimulation of PBMC ranged from 292 to 3,942 cpm. ${ }^{\| S I}$ (cpm in cultures with Ag/cpm in cultures without Ag or GST) (for BV13); BV13, extracellular portion of BPAG2; PVhis, extracellular portion of desmoglein 3 , the autoantigen of PV. SI $\geq 3$ was considered positive. 
Expression and purification of recombinant human BPAG2 and glutathione-S-transferase (GST) proteins. Three recombinant baculovirus-encoded proteins were used: BV13, consisting of the ECD of BPAG2 (residues 485-1430) linked to GST and 6x His tag (21); BV4, containing residues 804-1430 of the ECD of BPAG2 linked to a FLAG tag (IBI, Eastman Kodak, New Haven, CT) (24); and PVhis, containing the entire ECD of desmoglein 3 (Dsg3), the autoantigen of PV, linked to E-tag and 6x His (18). The exact location of the regions of the ECD of BPAG2 that are represented by the two recombinant proteins, BV13 and BV4, is shown in Fig. 1. The generation of recombinant BV13, BV4, and PVhis baculovirus and the expression of the BV13 (21), BV4 (24), and PVhis (18) baculoproteins by Spodoptera frugiperda insect cells have been described elsewhere. BV13 and PVhis proteins were purified over Nickel-NTA agarose $(18,21)$ while BV4 protein was purified by passage over columns bearing antiFLAG IgG (24) according to the manufacturers' recommendations. Recombinant GST protein was purified over agarose bearing antiGST IgG according to the manufacturers' recommendations (PharMingen, San Diego, CA).

Reagents and $m A b$. Tetanus toxoid (TT) was a gift from Behring (Marburg, Germany). Mouse IgG2a and mAb against CD3, CD4, CD45RA, CD45RO, TCR $\alpha / \beta$, and TCR $\gamma / \delta$ were purchased from Becton Dickinson (San Jose, CA) and mouse IgG1 from PharMingen. FITC-conjugated goat anti-mouse $\mathrm{Ab}$ (used at a dilution of 1:100) was obtained from Tago (Burlingame, CA).

Table II. HLA II Alleles and Proliferative Responses to BPAG2 of Peripheral Blood Lymphocytes from 24 Healthy Individuals

\begin{tabular}{|c|c|c|c|c|c|c|}
\hline \multirow[b]{2}{*}{ Donor } & \multirow[b]{2}{*}{ Age } & \multicolumn{2}{|c|}{ HLA class II alleles } & \multicolumn{3}{|c|}{ First $\mathrm{T}$ cell response* } \\
\hline & & HLA-DRB1 & HLA-DQB1 & BV13 $3^{\ddagger}$ & PVhis & $\mathrm{TT}^{\ddagger}$ \\
\hline & $y r$ & & & & & \\
\hline Co1 & 31 & 1301,1501 & 0602,- & 0.9 & 0.2 & 8.6 \\
\hline $\mathrm{Co} 2$ & 38 & 0101,0404 & 0302,0501 & 0.3 & 4.5 & 4.6 \\
\hline $\mathrm{Co} 3$ & 30 & 0401,1301 & $\mathbf{0 3 0 1}, 0603$ & 8.8 & 2.9 & 4.6 \\
\hline $\mathrm{Co} 4$ & 25 & 0101,1501 & 0501,0602 & 0.6 & 0.2 & 2.7 \\
\hline $\operatorname{Co} 5$ & 23 & 0402,1501 & 0302,0602 & 0.6 & 0.1 & 12.9 \\
\hline Co6 & 25 & 0301,1301 & 0201,0603 & 0.7 & 0.3 & 6.9 \\
\hline $\mathrm{Co} 7$ & 27 & 0101,0404 & 0302,0501 & 1.6 & 0.2 & 3.6 \\
\hline $\mathrm{Co} 8$ & 26 & $1302,-$ & $0604,-$ & 2.6 & 0.5 & 2.9 \\
\hline $\mathrm{Co} 9$ & 29 & 0102,1301 & 0501,0603 & 0.8 & 0.2 & 9.7 \\
\hline Co10 & 24 & 0102,0401 & $\mathbf{0 3 0 1}, 0501$ & 5.7 & 3.5 & 6.5 \\
\hline Co11 & 36 & 1101,1501 & $\mathbf{0 3 0 1}, 0602$ & 10.1 & 4.1 & 6.7 \\
\hline Co12 & 25 & 1101,1401 & $\mathbf{0 3 0 1}, 0503$ & 8.8 & 5.1 & 3.1 \\
\hline Co13 & 45 & 1203,1301 & $\mathbf{0 3 0 1}, 0603$ & 6.6 & 4.6 & 22.0 \\
\hline Co14 & 48 & 0701,1501 & 0201,0602 & 1.4 & 1.9 & 4.7 \\
\hline Co15 & 43 & 0101,0408 & $\mathbf{0 3 0 1}, 0501$ & 3.8 & 3.3 & 14.5 \\
\hline Co16 & 32 & 1101,1501 & $\mathbf{0 3 0 1}, 0602$ & 4.1 & 5.6 & 13.1 \\
\hline Co17 & 26 & 1104,1301 & $\mathbf{0 3 0 1}, 0603$ & 3.8 & 1.2 & 12.3 \\
\hline Co18 & 24 & 0301,1601 & 0201,0502 & 2.8 & 3.6 & 11.9 \\
\hline Co19 & 28 & 1301,1501 & 0602,0603 & 0.6 & 1.1 & 2.6 \\
\hline Co20 & 25 & 1101,1203 & 0301,- & 1.3 & 1.0 & 13.5 \\
\hline Co21 & 27 & 0301,0701 & 0201,- & 0.8 & 0.5 & 22.4 \\
\hline $\mathrm{Co} 22$ & 25 & 0301,1104 & $0201, \mathbf{0 3 0 1}$ & 0.2 & 1.4 & 23.8 \\
\hline $\mathrm{Co} 23$ & 30 & 0101,- & $0501,-$ & 1.1 & 3.6 & 11.9 \\
\hline Co24 & 26 & 0101,0405 & 0501,0602 & 2.1 & 3.7 & 18.1 \\
\hline
\end{tabular}

* Background stimulation of PBMC ranged from 516 to $3,958 \mathrm{cpm} .{ }^{\ddagger} \mathrm{SI}$ (cpm in cultures with $\mathrm{Ag} / \mathrm{cpm}$ in cultures without $\mathrm{Ag}$ or GST) (for BV13); BV13, extracellular portion of BPAG2; PVhis, extracellular portion of desmoglein 3 , the autoantigen of PV. SI $\geq 3$ was considered positive.
Culture media. PBMC were cultured in RPMI 1640 (GIBCO BRL, Gaithersburg, MD) with $10 \%$ pooled human serum (Sigma Chemical Co., St. Louis, MO) and $20 \mathrm{mM}$ L-glutamine (all from GIBCO BRL). Culture media with 10\% FCS (Boehringer Mannheim, Mannheim, Germany) were used for the expansion of BPAG2specific $\mathrm{T}$ cell lines and clones (after stimulation with 1\% PHA; GIBCO BRL). Spodoptera frugiperda insect cells (Invitrogen, San Diego, CA) were maintained in Grace's medium (GIBCO BRL) with $10 \%$ FCS, penicillin/streptomycin (GIBCO BRL), and L-glutamine or in Sf-900 serum-free insect medium (GIBCO BRL). Mouse L cells were cultured in DMEM (GIBCO BRL) with $10 \%$ FCS, penicillin/ streptomycin, L-glutamine, and $250 \mu \mathrm{g} / \mathrm{ml} \mathrm{G} 418$ (GIBCO BRL).

Generation of BPAG2-specific T cell lines and clones. BPAG2-specific $\mathrm{T}$ cell populations were established as described previously (18). In short, $2-3 \times 10^{5} \mathrm{PBMC}$ from BP patients and healthy donors were cultured in 200- $\mu$ l round-bottomed microtiter wells (Falcon, Oxnard, CA) with BV13 $(5-10 \mu \mathrm{g} / \mathrm{ml})$ and received $20 \mathrm{U} / \mathrm{ml} \mathrm{IL-2} \mathrm{(Biotest,}$ Mannheim, Germany) after 7 d. $10^{5}$ BV13-specific T cells were restimulated periodically with BV13 and $10^{5}$ autologous x-irradiated (5,000 R) PBMC and expanded with $20 \mathrm{U} / \mathrm{ml} \mathrm{IL-2}$ resulting in BV13specific $\mathrm{T}$ cell lines after the third stimulation with antigen $(\mathrm{Ag})$. The specificities of the in vitro stimulation with $\mathrm{Ag}$ were determined by the incorporation of $\left[{ }^{3} \mathrm{H}\right]$ thymidine (DuPont, Mechelen, Belgium) in cultures with $\mathrm{T}$ cells, BV13, and autologous $\mathrm{x}$-irradiated PBMC as $\mathrm{Ag}$-presenting cells (APC). T cell clones were generated from three $\mathrm{BP}$ patients (BP2, BP21, and BP28) with active BP disease after the second stimulation of PBMC with BV13 by standard limiting dilution techniques (18).

Ag responses and HLA class II restriction. $3 \times 10^{5} \mathrm{PBMC}$ were cultured with GST $(5-10 \mu \mathrm{g} / \mathrm{ml})$, BV13 $(5-10 \mu \mathrm{g} / \mathrm{ml})$, TT $(3.2 \mathrm{Lf} / \mathrm{ml})$, and PHA (1\%) in triplicate in 200- $\mu$ l round-bottomed wells (Falcon) at $37^{\circ} \mathrm{C}$ in $5 \% \mathrm{CO}_{2}$ for $6 \mathrm{~d}$. In proliferation assays with Ag-specific T cell lines and clones, $3-4 \times 10^{4} \mathrm{~T}$ cells were cultured with $\mathrm{Ag}$ (5-10 $\mu \mathrm{g} / \mathrm{ml})$ and $5-10 \times 10^{4}$ autologous, $\mathrm{x}$-irradiated (5,000 R) PBMC as APC. Ag-dependent T cell proliferation was determined by the incorporation of $\left[{ }^{3} \mathrm{H}\right]$ thymidine which was added to the cultures $18 \mathrm{~h}$ before termination of the assay. $\mathrm{T}$ cell proliferation was expressed as a stimulation index (SI) which is the ratio of $\left[{ }^{3} \mathrm{H}\right]$ thymidine uptake in cultures with Ag and cultures without Ag or with GST (as a control to cultures with BV13). SI $\geq 3$ was considered as a positive response. For HLA class II restriction experiments, $5 \times 10^{4}$ BPAG2-specific T cells were cultured with 5-10 $\times 10^{4} \mathrm{x}$-irradiated (5,000 R) PBMC with known HLA class II alleles as APC, and T cell proliferation was determined by the uptake of $\left[{ }^{3} \mathrm{H}\right]$ thymidine after $72 \mathrm{~h}$. HLADRB1*1101-transfected mouse L cells were also used as APC. L cells were grown to confluence, recovered by trypsinization, and $\mathrm{x}$-irradiated $(4,000 \mathrm{R})$ as described previously (25). $4 \times 10^{4} \mathrm{~T}$ cells were cultured with $4 \times 10^{4} \mathrm{~L}$ cells with and without BV13 $(5-20 \mu \mathrm{g} / \mathrm{ml})$, and $\left[{ }^{3} \mathrm{H}\right]$ thymidine was added for the final $18 \mathrm{~h}(25)$.

Cytokine production of BPAG2-specific T cells. Supernatants from cultures with autoreactive T cell lines and clones were harvested $72 \mathrm{~h}$ after stimulation with $\mathrm{Ag}$ and autologous, x-irradiated PBMC as APC; supernatants from cultures containing only T cells and APC or APC and Ag, respectively, served as controls. The immunoreactivities of the culture supernatants for IL-5, IL-13, and IFN- $\gamma$ were determined in duplicate or triplicate by ELISA (IL-4 and IFN- $\gamma$ : Duoset, Genzyme, Boston, MA; IL-5 and IL-13: Immunotech, Munich, Germany).

\section{Results}

In vitro responses of $P B M C$ from $B P$ patients and healthy donors to BPAG2. PBMC from $16 \mathrm{BP}$ patients and 24 healthy donors were cultured in vitro with BV13, an eukaryotic recombinant protein consisting of the ECD of BPAG2 (Fig. 1). 13 BP patients had active skin disease and 3 had no skin lesions (Table I). All 16 BP patients had detectable serum autoanti- 
Table III. Specificity and Cytokine Production of BPAG2-specific T Cell Lines from Patients with BP and HLA-DQB1*0301 Positive Normals (Co)

\begin{tabular}{|c|c|c|c|c|c|c|c|}
\hline Donor & $\mathrm{GST}^{*}$ & BV13* & BV4* & $\mathrm{TT}^{*}$ & IL- $5^{\ddagger}$ & IL-13 & IFN- $\gamma^{\ddagger}$ \\
\hline BP2 & $3996 \pm 752$ & $37109 \pm 565$ & $26019 \pm 1034$ & $1531 \pm 68$ & 2.3 & 1.7 & 8.9 \\
\hline BP21 & $841 \pm 156$ & $28310 \pm 2950$ & NT & $2083 \pm 289$ & 4.0 & NT & $<0.05$ \\
\hline BP24 & $632 \pm 123$ & $6736 \pm 367$ & NT & $1579 \pm 358$ & 4.1 & 2.3 & 8.8 \\
\hline BP28 & $770 \pm 155$ & $7378 \pm 1392$ & $10907 \pm 1278$ & $872 \pm 33$ & 2.1 & 1.3 & 1.1 \\
\hline BP42 & $609 \pm 13$ & $9824 \pm 1614$ & $8451 \pm 3513$ & $2056 \pm 224$ & 3.4 & 2.2 & 2.6 \\
\hline Co3 & $434 \pm 245$ & $7801 \pm 2005$ & $8945 \pm 2449$ & $1043 \pm 808$ & $<0.04$ & $<0.2$ & 8.8 \\
\hline Co11 & $1296 \pm 291$ & $30256 \pm 7074$ & $23611 \pm 4706$ & $1129 \pm 158$ & $<0.04$ & $<0.2$ & 7.1 \\
\hline Co12 & $1405 \pm 486$ & $8173 \pm 1119$ & $10391 \pm 6393$ & $1276 \pm 846$ & $<0.04$ & $<0.2$ & 6.4 \\
\hline
\end{tabular}

* Proliferative response of $\mathrm{T}$ cell lines was determined by $\left[{ }^{3} \mathrm{H}\right]$ thymidine incorporation $(\mathrm{cpm} \pm \mathrm{SD}) . N T$, not tested. ${ }^{\ddagger}$ Immunoreactivities of culture supernatants from Ag-stimulated autoreactive T cell lines for IL-5, IL-13, and IFN- $\gamma$ were determined by ELISA $\left(\mathrm{pg} / \mathrm{ml} \times 10^{-3}\right)$.

bodies against BPAG2, as determined by ELISA with BV13 protein (21) (Table I). 13 of the $16 \mathrm{BP}$ patients with autoantibodies against BPAG2 showed significant autoreactive $\mathrm{T}$ cell responses $(\mathrm{SI} \geq 3$ ) upon primary in vitro stimulation with BV13 whereas $3 \mathrm{BP}$ patients did not exhibit significant primary $\mathrm{T}$ cell responses to BPAG2 (Table I). There was no apparent correlation between the extent of proliferative response to BPAG2 and disease activity since PBMC from three BP patients without clinical symptoms proliferated to BPAG2 (Table I). T cell responsiveness to BPAG2 also seemed to be independent from the duration of disease (Table I). However, the extent of immunosuppressive therapy (particularly the doses of MP) seemed to negatively affect responsiveness of PBMC to BPAG2 (Table I).

10 of 12 HLA-typed BP patients with $\mathrm{T}$ cell responses to BPAG2 carried the DQB1*0301 allele which is prevalent in BP (Table I) (20). 1 of the $16 \mathrm{BP}$ patients exhibited T cell responses to Dsg3, the autoantigen of PV, an autoimmune blistering disease of the skin unrelated to BP (Table I). Autoreactive $\mathrm{T}$ cell responses to BPAG2 were also examined in 24 healthy individuals (Table II). 8 of 10 normal donors positive for the DQB1*0301 allele also showed significant $\mathrm{T}$ cell responses to BPAG2. In contrast, PBMC from 14 healthy individuals who carried HLA-DQ alleles other than DQB1*0301 did not show significant $T$ cell responses to BPAG2 (Table II). Of note, primary $\mathrm{T}$ cell responses to Dsg3, the autoantigen of PV, were also observed in 10 healthy donors (Table II). Except for one normal donor, these individuals carried the DQB1*0301 allele and/or the DQB1*0501 allele.

Specificity of autoreactive $T$ cell lines and clones to $B P A G 2$. Five BPAG2-specific long-term $\mathrm{T}$ cell lines were successfully generated from five BP patients. These $\mathrm{T}$ cell lines proliferated in culture with BV13 (ECD of BPAG2), but not with GST or TT as an irrelevant protein Ag (Table III). Three T cell lines from three DQB $1 * 0301$ positive healthy individuals were also uniformly stimulated by BV13 but not by GST or TT (Table III). 40 BPAG2-specific T cell clones were generated from the BP patients BP2 ( $n=15$; not shown), BP21 ( $n=14$; Fig. $2 A$ ) and BP28 $(n=11$; Fig. $3 A$ ). These T cell clones were uniformly stimulated by BV13 (ECD of BPAG2) (SI = 3.423 ) but not by GST (SI = 0.3-2.4) or TT (SI = 0.5-2.6). In addition to BV13, the recombinant BPAG2 protein BV4 which

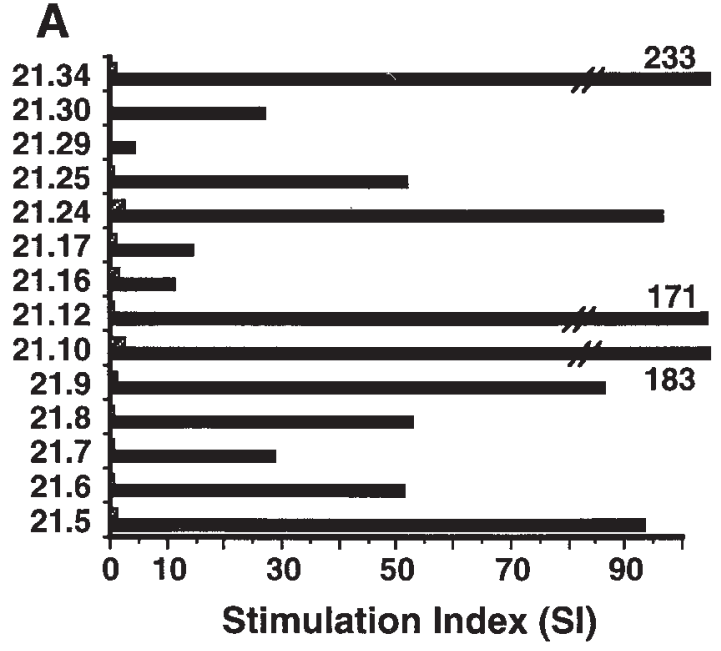
determined by ELISA and are expressed in $\mathrm{pg} / \mathrm{ml}$.
Figure 2. Ag specificity and cytokine production of BPAG2-responsive T cell clones from patient BP21 with BP. 14 autoreactive $\mathrm{T}$ cell clones were generated from BP patient BP21 who exhibited extensive blistering of the skin. T cells were cultured with $10 \mu \mathrm{g} / \mathrm{ml} \mathrm{BV} 13$ (ECD of BPAG2, black bars) or TT (4 Lf $/ \mathrm{ml}$, striped bars) and $\mathrm{x}$-irradiated, autologous PBMC as APCs for $48 \mathrm{~h}$. T cell proliferation was determined by $\left[{ }^{3} \mathrm{H}\right]$ thymidine incorporation (cpm) and is expressed as an SI (cpm in cultures with $\mathrm{Ag} / \mathrm{cpm}$ in cultures without $\mathrm{Ag}$ ) $(A)$. $\mathrm{SI} \geq 3$ was recognized as a positive response. Background proliferation ranged from 210 to $5,673 \mathrm{cpm}$. In other experiments (which are not shown), these T cell clones were consistently stimulated by BV13 but not by GST (data not shown). Before adding $\left[{ }^{3} \mathrm{H}\right]$ thymidine, $100-\mu 1$ samIL-5 IFN- $\gamma$ ples of culture supernatants were removed
culture supernatants for IL-5 and IFN- $\gamma$ were 


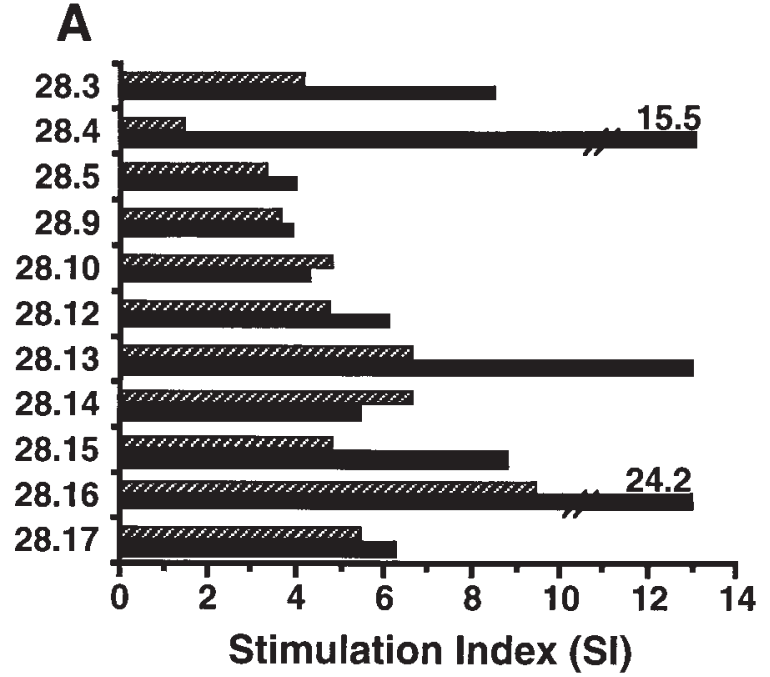

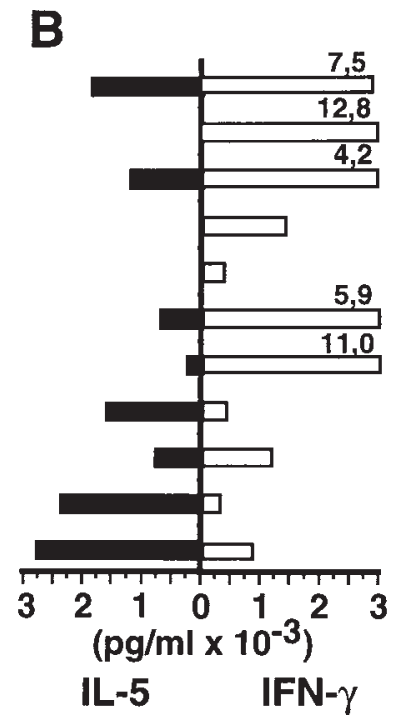

Figure 3. Ag specificity and cytokine production of BPAG2-responsive T cell clones from patient $\mathrm{BP} 28$ with BP. 11 autoreactive $\mathrm{T}$ cell clones were generated from BP patient BP28 who had extensive blistering of the skin. T cells were cultured with $10 \mu \mathrm{g} /$ $\mathrm{ml} \mathrm{BV13} \mathrm{(ECD} \mathrm{of} \mathrm{BPAG2,} \mathrm{black} \mathrm{bars)} \mathrm{or}$ $10 \mu \mathrm{g} / \mathrm{ml} \mathrm{BV4}$ (outer two-thirds of ECD of BPAG2, striped bars) and $\mathrm{x}$-irradiated, autologous PBMC as APCs for $48 \mathrm{~h}$. T cell proliferation was determined by the incorporation of $\left[{ }^{3} \mathrm{H}\right]$ thymidine $(\mathrm{cpm})$ and is expressed as an SI (cpm in cultures with $\mathrm{Ag}$ / cpm in cultures without $\mathrm{Ag})(A)$. In cultures with BV13, the SI represented the ratio of cpm in cultures with BV13/cpm in cultures with GST. SI $\geq 3$ was recognized as a positive response. Background proliferation ranged from 215 to $2,948 \mathrm{cpm}$. Before adding $[3 \mathrm{H}]$ thymidine, $100-\mu \mathrm{l}$ samples of culture supernatants were removed to determine the production of cytokines by BPAG2-reactive T cells $(B)$. The immunoreactivities of culture supernatants for IL-5 and IFN- $\gamma$ were determined by ELISA and are expressed in $\mathrm{pg} / \mathrm{ml}$. contains the distal two-thirds of the ECD of BPAG2 was also tested (Fig. 1). All six BPAG2-responsive T cell lines from the $\mathrm{BP}$ patients $\mathrm{BP} 2, \mathrm{BP} 28, \mathrm{BP} 42$ and the controls $\mathrm{Co} 3$, Co11, and Co12 were also stimulated by BV4 (Table III). 10 of 15 autoreactive $\mathrm{T}$ cell clones from $\mathrm{BP}$ patient $\mathrm{BP} 2(\mathrm{SI}=3.2-28.1)$ and 11 of $11 \mathrm{~T}$ cell clones from patient BP28 (Fig. $3 A$ ) were also stimulated significantly by BV4. Neither BV13 nor BV4 protein stimulated three TT-specific $\mathrm{T}$ cell lines generated from the peripheral blood of $\mathrm{BP}$ patients $\mathrm{BP} 2, \mathrm{BP} 21$, and $\mathrm{BP} 28(\mathrm{SI}=$ 1.2-2.2).

Phenotype and cytokine profile of BPAG2-specific T cells. Phenotypic analysis demonstrated that all autoreactive BPAG2specific $\mathrm{T}$ cell lines and clones were $\mathrm{CD} 4 / \mathrm{TCR} \alpha / \beta / \mathrm{CD} 45 \mathrm{RO}$ positive (Fig. 4). As a parameter of their biological function, the cytokine production of the BPAG2-specific $\mathrm{T}$ cell lines (Table III) and clones (Figs. $2 B$ and $3 B$ ) was investigated after $\mathrm{Ag}$ stimulation. Initially, culture supernatants were investigated for immunoreactivities of the Th1 cytokine IFN- $\gamma$ and the Th2 cytokines IL-4 and IL-5. Immunoreactivities for IL-4 were not detectable in supernatants of long-term proliferative assays with PBMC. In addition, IL-4 was only inconsistently detectable in supernatants from Ag-stimulated T cell lines and clones. An autoreactive T cell line and five of eight $\mathrm{T}$ cell clones from the patient BP28 produced only marginal levels of IL-4 ranging from 10 to $100 \mathrm{pg} / \mathrm{ml}$. Based on a recent study which demonstrated that IL-4 was produced by Ag-activated $\mathrm{CD}_{45 \mathrm{RO}^{+}} \mathrm{Th} 2$ cells for much shorter periods than the IL-4-associated cytokine IL-13 (26), we later investigated the production of IL-5 and IL-13 as a parameter of Th2 cell function.

All five BPAG2-specific T cell lines produced IL-5 and all four tested $\mathrm{T}$ cell lines produced IL-13 (Table III). In addition to these Th2 cytokines, autoreactive $\mathrm{T}$ cell lines from the BP patients BP2, BP24, BP28, and BP42 also produced the Th1 cytokine IFN- $\gamma .10$ of $14 \mathrm{~T}$ cell clones from the BP patient $\mathrm{BP} 21$ produced predominantly IL-5 whereas the remaining $4 \mathrm{~T}$ cell clones produced IFN- $\gamma$ and IL-5 (Fig. $2 B$ ). The majority $(8 / 11)$ of autoreactive $T$ cell clones generated from patient BP28 produced both IL-5 and IFN- $\gamma$ or IFN- $\gamma$ alone whereas three clones secreted predominantly IL-5 (Fig. 3 B). In contrast, three autoreactive $\mathrm{T}$ cell lines from the three DQB1*0301 positive healthy individuals produced IFN- $\gamma$, but no IL-5 or IL-13 upon Ag stimulation (Table III). Autoreactive $\mathrm{T}$ cell lines from BP patients and normal patients were stimulated to a similar extent by BV13 at concentrations ranging from 5 to $20 \mu \mathrm{g} / \mathrm{ml}$. The production of IFN- $\gamma$ and IL-5 positively correlated with the extent of proliferative $\mathrm{T}$ cell responses.

There was no apparent correlation between IL-5 or IFN- $\gamma$ secretion and $\mathrm{Ab}$ production as the $\mathrm{T}$ cell lines from patients BP2, BP24, BP28, and BP42 with high autoantibody titers $(>1: 100)$ produced both IL-5 and IFN- $\gamma$ (Table III). Cytokine production was not investigated in primary cultures with PBMC of the other BP patients because of high backgrounds for both IL-5 and IFN- $\gamma$ (data not shown).

Immunogenetic restriction of autoreactive $T$ cell responses to BPAG2. Since 10 of 12 HLA-typed BPAG2-responsive $\mathrm{BP}$ patients and 8 of $10 \mathrm{BPAG} 2$-reactive healthy individuals carried the DQB1*0301 allele, we next investigated whether DQB1*0301 restricted BPAG2-specific $\mathrm{T}$ cell responses. Three $\mathrm{CD}^{+}{ }^{+} \mathrm{T}$ cell lines from the DQB1*0301 positive BP patients BP2 and BP28 and the DQB1*0301 positive normal Co12 were cultured with BPAG2 and $\mathrm{x}$-irradiated allogeneic PBMC with known HLA class II alleles as APC. All T cell lines showed a vigorous proliferative response to BPAG2 with autologous PBMC as APC or with allogeneic APC that expressed the DQB1*0301 allele. In contrast, none of these $\mathrm{T}$ cell lines developed a significant proliferative response to BPAG2 with APC expressing HLA class II alleles other than DQB1*0301 (Fig. 5). There was also no significant $\mathrm{T}$ cell response to BPAG2 upon coculture of the $\mathrm{T}$ cell lines BP2, BP28, and Co12 with DRB1*1101-transfected L cells as APC 

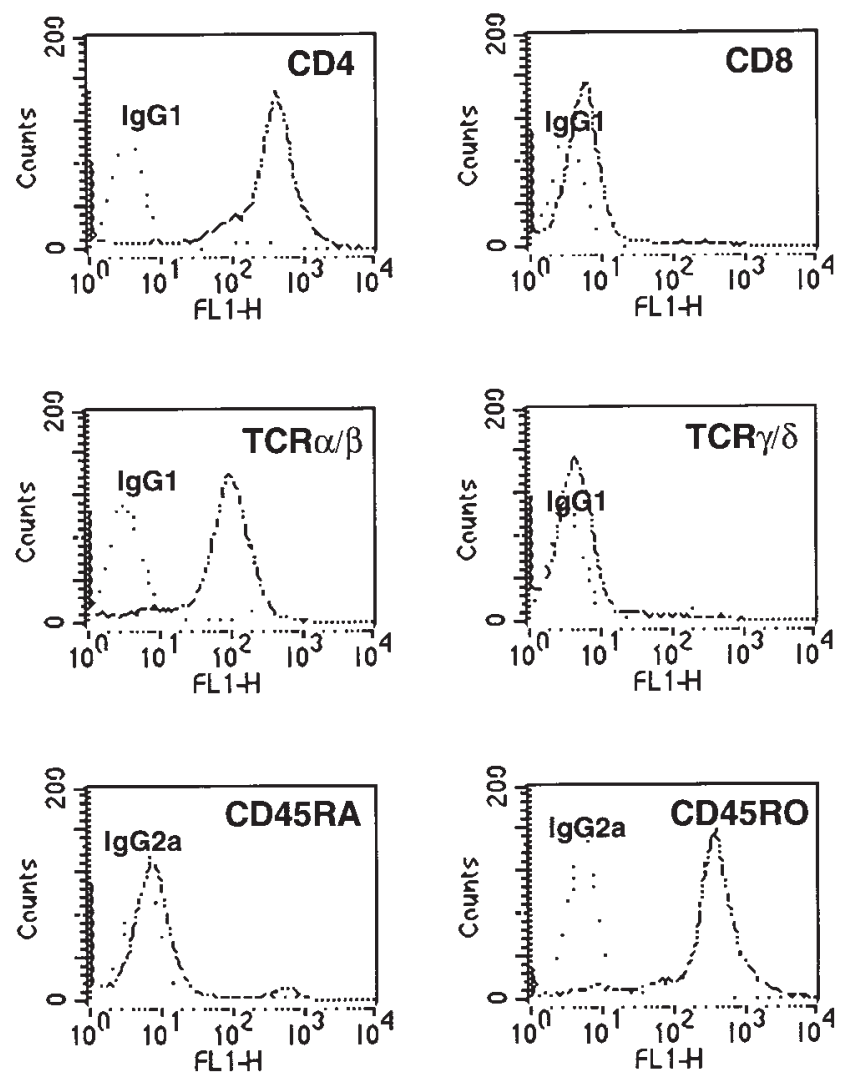

Figure 4. Cell surface phenotype of BPAG2-specific T cells. The expression of cell surface markers of BPAG2-specific T cells was determined by FACS ${ }^{\circledR}$ analysis using mouse anti-human mAbs as shown; mouse IgG served as a control. Fluorescein-conjugated goat antimouse IgG was used as a second $\mathrm{Ab}$. In each histogram, the green fluorescence $(F L 1-H)$ of cells stained with the specific $\mathrm{Ab}$ (dashed and dotted line) is compared with the background cell fluorescence with the isotype control (dotted line). Shown here is the representative phenotypic analysis of the T cell clone BP28.3.

(SI $=0.3-2.9$, background: $1,039 \pm 313 \mathrm{cpm})$. The differential stimulation of T cell line BP28 with autologous $(\mathrm{SI}=45.8)$ and allogeneic DQB1*0301 ${ }^{+}$PBMC $(\mathrm{SI}=13.9)$ as APC was thus most likely based on intraexperimental variations with different APC (Fig. 5). HLA-DQB1*0301 ${ }^{+}$L cells were not available to be used as APC. These data strongly suggest that the BP-associated DQB1*0301 allele restricts autoreactive $\mathrm{T}$ cell responses to BPAG2.

\section{Discussion}

This study investigated whether patients with the autoimmune blistering disease, $\mathrm{BP}$, exhibit $\mathrm{T}$ cell responses against BPAG2, a cell adhesion molecule in the epidermal basement membrane $(4,5,7,13)$. Autoantibodies against BPAG2 are thought to play a key role in the pathogenesis of this disease (11-13). Our results demonstrate that the majority (13/16) of adult patients with BP have autoreactive $\mathrm{T}$ cells that recognize epitopes of the ECD of BPAG2, as assessed by using two recombinant proteins encompassing major portions of the ECD of BPAG2 (Fig. 1). Autoreactive T cell lines and clones generated from five BP patients expressed a $\mathrm{CD} 4 / \mathrm{TCR} \alpha / \beta$ positive memory cell phenotype. This finding extends recent studies leading to the identification of autoreactive $\mathrm{CD} 4^{+}$memory $\mathrm{T}$ cells in the Ab-mediated autoimmune diseases autoimmune thyroiditis (17), myasthenia gravis (16), and PV, an autoimmune blistering disease of the skin associated with circulating autoantibodies against the desmosomal adhesion molecule, Dsg3 $(18,19)$.

The majority (12/15) of the HLA-typed BP patients carried the DQB1*0301 allele. This particular HLA class II allele has been shown recently to be prevalent in BP (20). HLADQ $\beta 1 * 0301$ may thus be involved in the presentation of immunodominant epitopes of BPAG2 to autoreactive T cells in BP. Indeed, two CD4 ${ }^{+}$BPAG2-specific $\mathrm{T}$ cell lines from two BP patients were restricted by the HLA-DQB1*0301 allele. Despite the limited number of patients studied, this observation suggests that this prevalent HLA class II allele plays an important role in restricting autoreactive $\mathrm{T}$ cell responses to BPAG2. These findings are in contrast to recent observations in PV which is also characterized by a prevalence of particular HLA class II alleles (27). Autoreactive T cell responses of PV patients to Dsg3, the autoantigen of PV, were not only restricted by the PV susceptibility HLA class II alleles DRB1*0402 $(19,25,28)$ and DRB1*1401 (19), but also by the unrelated DQB1*0301 allele (25). Furthermore, Dsg3-specific $\mathrm{T}$ cell responses of healthy individuals were restricted by several HLA-DR11 alleles homologous to DRB1*0402 (25) and DQB1*0301 (25).

A major finding of this study was the identification of autoreactive $\mathrm{T}$ cell responses to BPAG2 in a subset of healthy individuals. 8 of 10 healthy carriers of the HLA-DQB1*0301 allele showed primary $\mathrm{T}$ cell responses to BPAG2. The DQB1*0301 allele was also found to restrict the proliferative $\mathrm{T}$ cell response to BPAG2 in one healthy donor. In contrast, 14 healthy individuals who carried HLA-DQ alleles other than DQB1*0301 did not mount significant primary $T$ cell responses to BPAG2. These findings suggest that the HLADQB1*0301 allele is associated with the ability to develop T cell proliferative responses to BPAG2 independent of BP. The presence of autoreactive $\mathrm{T}$ cell clones in the immune repertoire of healthy donors is not unexpected since autoreactive $\mathrm{T}$ cells specific for the autoantigen of multiple sclerosis (29), myasthenia gravis (30), and PV (18) were also identified in healthy carriers of the disease-associated HLA class II alleles or of HLA class II alleles homologous to the alleles prevalent in these autoimmune diseases. In light of these studies, primary responses to Dsg3, the autoantigen of PV, were also observed in this study in a single BP patient and in 10 healthy donors. 10 of 11 of these individuals carried the DQB $1 * 0301$ allele, which has been shown recently to also restrict Dsg3driven $\mathrm{T}$ cell responses in PV patients and normal patients (25), and/or the DQB1*0501 allele, which is homologous to the major susceptibility allele of PV, DQB1*0503 (31).

Most of the BPAG2-specific $\mathrm{T}$ cell lines and clones were stimulated by a recombinant form of BPAG2, BV4, that lacked the proximal one-third of the ECD of BPAG2 (i.e., the portion closest to the plasma membrane of basal keratinocytes) (7). This observation indicates that these autoreactive $\mathrm{T}$ cell populations recognized epitopes of the distal two-thirds of the ECD of BPAG2. However, T cell epitopes are also located within the proximal one-third of the ECD of BPAG2 since five BPAG2-responsive $\mathrm{T}$ cell clones from $\mathrm{BP}$ patient $\mathrm{BP} 2$ were not stimulated by BV4. This finding is of particular 


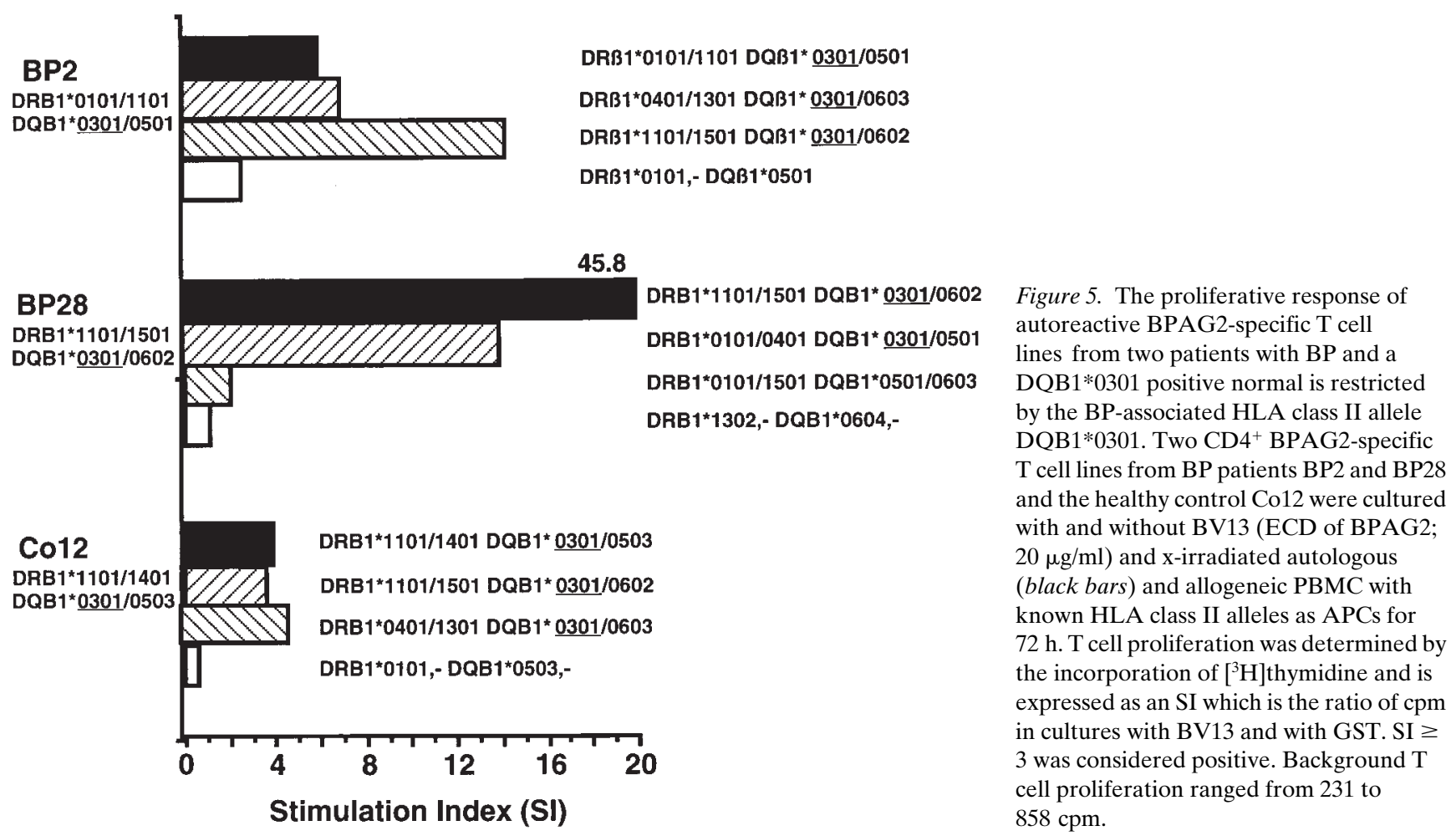

interest since the putative major B cell epitopes of BPAG2 are located in a distinct noncollagenous region of the ECD adjacent to the transmembranous region, which is not contained in the BV4 protein (13-15). Sera from BP patients BP2 and BP28 also contained $\mathrm{IgG}$ reactive with $\mathrm{BV} 4$, which strongly suggests that antibody epitopes are also located in the distal two-thirds of the ECD of BPAG2.

Our findings demonstrate that autoreactive $\mathrm{T}$ cell lines and clones from five BP patients produced both Th1 and Th2 cytokines. Although the Th 2 cytokines IL- 4 and IL-13 have been shown to regulate the secretion of $\mathrm{IgG} 4$ and $\mathrm{IgE}$ by activated B cells (32-35), the Th1 cytokine IFN- $\gamma$ induces the secretion of IgG1 (36). Both autoreactive Th1 and Th2 cells may be involved in the regulation of the production of pathogenic autoantibodies by B cells in BP. Sera of patients with BP contain predominantly autoantibodies of the IgG4 subclass directed against the dermo-epidermal basement membrane zone (37, 38). In addition, BP patients with severe disease exhibit IgE autoantibodies against the major BP Ags (39). Autoantibodies of the IgG1 subclass are also present in the sera of BP patients, although at lower concentrations than $\operatorname{IgG} 4(37,38)$. Since blister formation in an animal model of BP required the activation of complement $(12,40)$, the complement-binding IgG1 autoantibody may also contribute to the pathogenesis of BP. Autoreactive Th 2 cells may be critically involved in the initiation of the production of pathogenic autoantibodies in BP since BPAG2-reactive healthy normal donors exhibited only Th1 responses to BPAG2. In this study, there was no apparent correlation between the production of either IL-5 or IFN- $\gamma$ and antibody production since the $\mathrm{T}$ cell lines from patients $\mathrm{BP} 2, \mathrm{BP} 24, \mathrm{BP} 28$, and BP42 with high autoantibody titers produced both IL-5 and IFN- $\gamma$ (Table III).

To our knowledge, this is the first report describing autoreactive Th1 and Th2 responses to BPAG2, the presumptive ma-

jor autoantigen of BP, which were restricted by the BP-associated DQB1*0301 allele in two BP patients. In contrast, healthy carriers of DQB1*0301 mounted exclusively Th1 cell responses to BPAG2. The identification of epitopes of BPAG2 which are recognized by autoreactive $\mathrm{T}$ cells may eventually facilitate the development of specific immunological strategies not only for the treatment of BP, but also of related autoimmune blistering diseases, such as cicatricial pemphigoid (41) and pemphigoid gestationis (42), which not only share BPAG2 as the major autoantigen but also DQB1*0301 as the predisposing HLA class II allele.

\section{Acknowledgments}

We thank Dr. Robert Karr for providing HLA-DR11-transfected L cell lines and Dr. Joachim Grötzinger and Regine Riechers for critically reading the manuscript.

This study was supported by the Deutsche Forschungsgemeinschaft (He 1602/5-2), Bonn, Germany. L. Büdinger is a recipient of a doctoral training stipend by the IZKF (Interdisciplinary Center for Clinical Research) BIOMAT, RWTH Aachen, Germany. L. Borradori has been supported by the Swiss National Foundation for Scientific Research (32-51083.97).

\section{References}

1. Lever, W.F. 1953. Pemphigus. Medicine. 32:1-123.

2. Jordon, R.E., E.H. Beutner, E. Witebsky, G. Blumental, W.C. Hale, and W.F. Lever. 1967. Basement zone antibodies in bullous pemphigoid. J. Am. Med. Assoc. 200:751-756.

3. Stanley, J.R., P. Hawley-Nelson, S.H. Yuspa, E.M. Shevach, and S.I. Katz. 1981. Characterization of bullous pemphigoid antigen: a unique basement membrane protein of stratified epithelia. Cell. 24:897-903.

4. Mutasim, D.F., Y. Takahashi, R.S. Labib, G.J. Anhalt, H.P. Patel, and L.A. Diaz. 1985. A pool of bullous pemphigoid antigen is intracellular and associated with the basal cell cytoskeleton-hemidesmosome complex. J. Invest. Dermatol. 84:47-53. 
5. Regnier, M., P. Vaigot, S. Michel, and M. Prunieras. 1985. Localization of bullous pemphigoid antigen (BPA) in isolated human keratinocytes. J. Invest. Dermatol. 85:187-190.

6. Yang, J., J. Dowling, Q.C. Yu, P. Kouklis, D.W. Cleveland, and E. Fuchs. 1996. An essential cytoskeletal linker protein connecting actin microfilaments to intermediate filaments. Cell. 86:655-665.

7. Giudice, G.J., D.J. Emery, and L.A. Diaz. 1992. Cloning and primary structural analysis of the bullous pemphigoid autoantigen BP180. J. Invest. Dermatol. 99:243-250.

8. Borradori, L., P.J. Koch, C.M. Niessen, S. Erkeland, M.R. van Leusden, and A. Sonnenberg. 1996. The localization of bullous pemphigoid antigen 180 (BP180) in hemidesmosomes is mediated by its cytoplasmic domain and seems to be regulated by the $\beta 4$ integrin subunit. J. Cell Biol. 136:1333-1347.

9. Hopkinson, S.B., S.E. Baker, and J.C.R. Jones. 1995. Molecular genetic studies of a human epidermal autoantigen (the 180-kD bullous pemphigoid antigen/BP180). Identification of functionally important sequences within the BP180 molecule and evidence for an interaction between BP180 and $\alpha 6$ integrin. J. Cell Biol. 130:117-125.

10. McGrath, J.A., B. Gatalica, A.M. Christiano, K.H. Li, K. Owaribe, J.R. McMillan, R.A.J. Eady, and J. Uitto. 1995. Mutations in the $180-\mathrm{kD}$ bullous pemphigoid antigen (BPAG2), a hemidesmosomal transmembrane collagen (COL17A1), in generalized atrophic benign epidermolysis bullosa. Nat. Genet. 11:83-86.

11. Liu, Z., L.A. Diaz, J.L. Troy, A.F. Taylor, D.J. Emery, J.A. Fairley, and G.J. Giudice. 1993. A passive transfer model of the organ-specific autoimmune disease, bullous pemphigoid, using antibodies generated against the hemidesmosomal antigen, BP180. J. Clin. Invest. 92:2480-2488.

12. Liu, Z., G.J. Giudice, S.J. Swartz, J.A. Fairley, G.O. Till, J.L. Troy, and L.A. Diaz. 1995. The role of complement in experimental bullous pemphigoid. J. Clin. Invest. 95:1539-1544.

13. Giudice, G.J., D.J. Emery, B.D. Zelickson, G.J. Anhalt, Z. Liu, and L.A. Diaz. 1993. Bullous pemphigoid and herpes gestationis autoantibodies recognize a common noncollagenous site on the BP180 ectodomain. J. Immunol. 151:5742-5750.

14. Zillikens, D., P.A. Rose, S.D. Balding, Z. Liu, M. Olague-Marchan, L.A. Diaz, and G.J. Giudice. 1997. Tight clustering of extracellular BP180 epitopes recognized by bullous pemphigoid autoantibodies. J. Invest. Dermatol. 109:573-579.

15. Zillikens, D., J.M. Mascaro, P.M. Rose, Z. Liu, S.M. Ewing, F. Caux, R.G. Hoffmann, L.A. Diaz, and G.J. Giudice. 1997. A highly sensitive enzymelinked immunosorbent assay for the detection of circulating anti-BP180 autoantibodies in patients with bullous pemphigoid. J. Invest. Dermatol. 109:679-683.

16. Brocke, S., C. Brautbar, and L. Steinman. 1988. In vitro proliferative responses and antibody titers specific to human acetylcholine receptor synthetic peptides in patients with myasthenia gravis and relation to MHC class II genes. J. Clin. Invest. 82:1894-1900.

17. Roitt, I.M. 1956. Autoantibodies in Hashimoto's disease (lymphadenoid goitre). Lancet. 2:820-828.

18. Hertl, M., M. Amagai, H. Sundaram, J.R. Stanley, K. Ishii, and S.I. Katz. 1998. Recognition of desmoglein 3 by autoreactive $T$ cells in pemphigus vulgaris patients and normals. J. Invest. Dermatol. 110:62-66.

19. Lin, M.S., S.J. Swartz, A. Lopez, X. Ding, M.A. Fernandez-Vina, P. Stastny, J.A. Fairley, and L.A. Diaz. 1997. Development and characterization of desmoglein 3-specific T cells from patients with pemphigus vulgaris. J. Clin. Invest. 99:31-40.

20. Delgado, J.C., D. Turbay, E.J. Yunis, E.D. Morton, K. Bhol, R. Norman, C.A. Alper, R.A. Good, and A.R. Ahmed. 1996. A common major histocompatibility complex class II allele HLA-DQ $\beta 1^{*} 0301$ is present in clinical variants of pemphigoid. Proc. Natl. Acad. Sci. USA. 93:8569-8571.

21. Haase, C., L. Büdinger, L. Borradori, C. Yee, H.F. Merk, K.B. Yancey, and M. Hertl. 1998. Detection of IgG autoantibodies in the sera of patients with bullous and gestational pemphigoid: ELISA studies utilizing a baculovirusencoded form of bullous pemphigoid antigen 2. J. Invest. Dermatol. 110:282-286.

22. Olerup, O., and H. Zetterquist. 1992. HLA-DR typing by PCR amplification with sequence specific primers (PCR-SSP) in 2 hours: an alternative to serological DR typing in clinical practice including donor-recipient matching in cadaveric transplantation. Tissue Antigens. 39:225-235.

23. Olerup, O., A. Aldener, and A. Fogdell. 1993. HLA-DQB1 and HLA-
DQA1 typing by PCR amplification with sequence specific primers (PCR-SSP) in 2 hours. Tissue Antigens. 41:119-134.

24. Masunaga, T., H. Shimizu, C. Yee, L. Borradori, Z. Lazarova, T. Nishikawa, and K.B. Yancey. 1997. The extracellular domain of BPAG2 localizes to anchoring filaments and its carboxyl terminus extends to the lamina densa of normal human epidermal basement membrane. J. Invest. Dermatol. 109:200206.

25. Hertl, M., R.W. Karr, M. Amagai, and S.I. Katz. 1998. Heterogeneous MHC II restriction pattern of autoreactive desmoglein 3-specific T cell responses in pemphigus vulgaris. J. Invest. Dermatol. 110:388-392.

26. Jung, T., J. Wijdenes, C. Neumann, J.E. de Vries, and H. Yssel. 1996. Interleukin-13 is produced by activated human CD45RA + and CD45RO $+\mathrm{T}$ cells: modulation by interleukin-4 and interleukin-12. Eur. J. Immunol. 26:571577.

27. Ahmed, A.R., E.J. Yunis, K. Khatri, K. Wagner, G. Notani, Z. Awdeh, and C.A. Alper. 1990. Major histocompatibility complex haplotype studies in Ashkenazi Jewish patients with pemphigus vulgaris. Proc. Natl. Acad. Sci. USA. 87:7658-7662.

28. Wucherpfennig, K.W., B. Yu, K. Bhol, D.S. Monos, E. Argyris, R.W. Karr, A.R. Ahmed, and J.L. Strominger. 1995. Structural basis for major histocompatibility complex (MHC)-linked susceptibility to autoimmunity: charged residues of a single $\mathrm{MHC}$ binding pocket confer selective presentation of selfpeptides in pemphigus vulgaris. Proc. Natl. Acad. Sci. USA. 92:11935-11939.

29. Martin, R., R. Voskuhl, M. Flerlage, D.E. McFarlin, and H. McFarland. 1993. Myelin basic protein-specific T-cell responses in identical twins discordant or concordant for multiple sclerosis. Ann. Neurol. 34:524-535.

30. Fredrikson, S., J.B. Sun, W.H. Huang, B.L. Li, T. Olsson, and H. Link. 1993. Cord blood contains high number of autoimmune T cells recognizing multiple myelin proteins and acetylcholine receptor. J. Immunol. 151:2217-2224.

31. Sinha, A.A., C. Brautbar, F. Szafer, A. Friedmann, E. Tzfoni, J.A. Todd, L. Steinman, and H.O. McDevitt. 1988. A newly characterized HLA-DQß allele associated with pemphigus vulgaris. Science. 239:1026-1029.

32. Zhang, K., E.A. Clark, and A. Saxon. 1991. CD40 stimulation provides an interferon-gamma-independent and IL-4-dependent differentiation signal directly to human B cells for IgE production. J. Immunol. 146:1836-1842.

33. Gascan, H., J.F. Gauchat, M.G. Roncarolo, H. Yssel, H. Spits, and J.E. de Vries. 1992. Human B cell clones can be induced to proliferate and to switch to $\mathrm{IgE}$ and $\mathrm{IgG} 4$ synthesis by interleukin 4 and a signal provided by activated $\mathrm{CD}^{+}{ }^{+} \mathrm{T}$ cell clones. J. Exp. Med. 173:747-750.

34. Punnonen, J., G. Aversa, B.G. Cocks, A.N. McKenzie, S. Menon, G. Zurawski, R. de Waal Malefyt, and J.E. de Vries. 1993. Interleukin 13 induces interleukin-4-independent IgG4 and IgE synthesis and CD23 expression by human B cells. Proc. Natl. Acad. Sci. USA. 90:3730-3736.

35. Punnonen, J., and J.E. de Vries. 1994. IL-13 induces proliferation, Ig isotype switching, and Ig synthesis by immature human fetal B cells. J. Immunol. 152:1094-1101.

36. Romagnani, S. 1992. Human TH1 and TH2 subsets: regulation of differentiation and role in protection and immunopathology. Int. Arch. Allergy Appl. Immunol. 98:279-285.

37. Bird, P., P.S. Friedmann, N. Ling, A.G. Bird, and R.A. Thompson. 1986. Subclass distribution of IgG autoantibodies in bullous pemphigoid. J. Invest. Dermatol. 86:21-25.

38. Bernard, P., P. Aucouturier, F. Denis, and J.M. Bonnetblanc. 1990. Immunoblot analysis of IgG subclasses of circulating antibodies in bullous pemphigoid. Clin. Immunol. Immunopathol. 54:489-494.

39. Delaporte, E., A. Dubost-Brama, R. Ghohestani, J.F. Nicolas, J.L. Neyrinck, H. Bergoend, A. Janin, and M. Capron. 1996. IgE autoantibodies directed against the major bullous pemphigoid antigen in patients with a severe form of pemphigoid. J. Immunol. 157:3642-3647.

40. Liu, Z., G.J. Giudice, X. Zhou, S.J. Swartz, J.L. Troy, J.A. Fairley, G.O. Till, and L.A. Diaz. 1997. A major role for neutrophils in experimental bullous pemphigoid. J. Clin. Invest. 100:1256-1263.

41. Balding, S.D., C. Prost, L.A. Diaz, P. Bernard, C. Badane, D. Aberdam, and G.J. Giudice. 1996. Cicatricial pemphigoid autoantibodies react with multiple sites on the BP180 extracellular domain. J. Invest. Dermatol. 106:141-146.

42. Morrison, L.H., R.S. Labib, J.J. Zone, L.A. Diaz, and G.J. Anhalt. 1988. Herpes gestationis autoantibodies recognize a $180-\mathrm{kD}$ human epidermal antigen. J. Clin. Invest. 81:2021-2026. 